https://www.journal-imab-bg.org

Original article

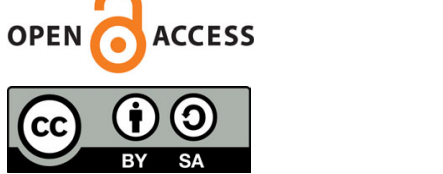

\title{
COMPARISON OF SKELETAL MATURITY AND CHRONOLOGICAL AGE IN BULGARIAN FEMALE AND MALE PATIENTS WITH TRANSVERSE MAXILLARY DEFICIT
}

\author{
Mariya Stoilova-Todorova, Silviya Krasteva, Georgi Stoilov, Katya Todorova- \\ Plachiyska. \\ Department of Orthodontics, Faculty of Dental Medicine, Medical University \\ of Plovdiv, Bulgaria
}

\begin{abstract}
:
Aim: The aim of this study was to compare the skeletal and chronological age of adolescent Bulgarian female and male patients with à transverse maxillary deficit in order to establish the level of consistencies and discrepancies within and between the two sexes.

Material and methods: The data included lateral cephalometric radiographs of 74 patients, among whom 51 girls and 23 boys. The patients' ages ranged between 9 and 17 years, with an average age of 13.2 years $( \pm 2.24)$. The assessment of skeletal maturation followed the cervical vertebral maturation (CVM) methods of Baccetti et al. and Lamparski. Comparison of skeletal and chronological age was performed for patients before age spurt and after age spurt within the female and male groups. The two sexes were compared in view of consistencies and discrepancies between chronological and skeletal age.

Results: The results showed a statistically lower percentage of consistencies and a higher percentage of discrepancies in patients before age spurt for both sexes. Vice versa, in patients after age spurt consistencies, constituted a statistically higher percentage for both sexes. As a whole, the female patients had a slightly higher percentage of consistency $(54 \%)$ between chronological and skeletal age than the male patients (48\%), but the difference of $6 \%$ was not statistically significant $p=0.73$. The discrepancies towards a higher skeletal age constituted $83 \%$ of the total number of discrepancies among the female patients, and $75 \%$ of the discrepancies among the male patients. The difference of $8 \%$ was not significant, $p=0.56$. The mean chronological age of the female and male patients in each CVS stage was very similar.

Conclusion: In patients with incomplete skeletal growth, skeletal age corresponds to a higher level of maturation than predicted by the patients' chronological age in both female and male patients. The two sexes show similar trends of accelerated skeletal maturation without statistically significant differences. Our results differ from previous findings of the existence of sexual dimorphism in skeletal age maturation.
\end{abstract}

Keywords: Orthodontic treatment, Skeletal maturity,
Chronological age, Sexual dimorphism

\section{INTRODUCTION:}

The effectiveness of orthodontic treatment of adolescent patients depends on the accurate assessment of their growth potential [1]. Various maturity indices have been used to identify growth stages, including chronological age, height, weight, sexual maturation, dental development, frontal sinus depth, and skeletal maturity $[1,2,3]$.

The precise estimation of growth potential is further complicated by the large variation among individuals caused by environmental and socioeconomic factors that can modulate a patient's growth and the subsequent onset of puberty peak [4]. In recent years there has been a process of rapid physical development among adolescents. Accelerated growth may affect the different metrics used to determine growth potential, including skeletal maturation and dental development [5,6]. Moreover, some research points at the existence of sexual dimorphism in the patterns of growth peak and a female predisposition to accelerated skeletal maturity [7, 8, 9]. Baidas (2012) is found that the mean chronological age of Saudi female adolescents in each cervical vertebral maturation stage was significantly lower than their male counterparts [8]. On the other hand, there are also studies which report an accelerated maturation rate in males $[2,10]$.

Acknowledging the multitude of factors that contribute to a young patient's growth potential, this study is focused on two of the most commonly used indicators of growth maturity, chronological age and skeletal maturity. Research about the relationship between chronological and skeletal maturity [9] shows that chronological age is a feeble predictor of a patient's skeletal maturity. However, research about this relationship in view of sexual dimorphism is still fairly scarce with controversial findings [8, 10].

The CVM is a more recent method of estimating skeletal age than the classical X-ray of the wrist bone. A number of studies have concluded that CVM is a valid indicator of skeletal growth and can be used with the same degree of credibility as the commonly accepted X-ray of the wrist bone [2]. CVM is also a safer method than the X-ray wrist bone assessment and easier to apply in clinical settings [11]. 
Our goal was to determine if sexual dimorphism is a factor that influences the relationship between chronological and skeletal age and the subsequent assessment of the growth potential of adolescent orthodontic patients within each sex and between the two sexes.

\section{MATERIALS AND METHODOLOGY:}

We collected data from 74 patients (51 girls and 23 boys) with orthodontic malocclusions that include transverse maxillary deficit, undergoing treatment at the Faculty of Dental Medicine, Plovdiv and private practice.

The patients' age ranged from 9 to 17 years with a mean age of $13.2( \pm 2.24)$ years $(13.36 \pm 2.18$ for females and $12.86 \pm 2.39$ for males). All patients were in the late mixed or early permanent dentition stage. To evaluate the skeletal age of the patients, we used lateral cephalometric radiographs, which had to satisfy the following criteria:

- The radiographs are clear and made according to the commonly accepted methodology for performing telegraph profiles.

- The vertebrae do not have morphological changes and are not affected by systemic diseases.

- All vertebrae C2 through C6 have visible limits.

We assessed skeletal age through changes in cervical spine development by combining the $\mathrm{CV}$ method proposed by Lamparski (1972) with the modified method of Bacchetti, Franchi and Mc Namara (2005). For precise cephalometric morphological characterization, we applied points determined by the Bacchetti methodology on the C2, C3, and $\mathrm{C} 4$ vertebrae and supplemented the methodology with the addition of identical points on the $\mathrm{C} 5$ and $\mathrm{C} 6$ vertebrae.

The presence of concavity was determined at the following points: $\mathrm{C} 2 \mathrm{~m}, \mathrm{C} 3 \mathrm{~m}$ and $\mathrm{C} 4 \mathrm{~m}$, located higher than the line connecting points $\mathrm{C} 2 \mathrm{p}, \mathrm{C} 2 \mathrm{a}, \mathrm{C} 3 \mathrm{lp}, \mathrm{C} 3 \mathrm{la}$, and respectively points C5lp, C5la, C6up and C6ua.

The patients' chronological age was coded in years and months. Months were represented in fractions as follows: $0.25=\leq 3$ months; $0.50=\leq 6$ months; $0.75=>6$ and $\leq 9$ months. The female and male patients were divided into two age groups each, according to an expected growth spurt. The patients between ages 9 and 13.50 years formed the group before the growth spurt, whereas those of ages between 13.75 and 17 formed the group after the growth spurt. Consistencies and discrepancies between patients' chronological age and skeletal maturity stage were calculated within each sex, and chi-square comparisons of proportions were carried out between the groups before and after the growth spurt.

\section{Statistical methods:}

The data were analyzed with the Statistical Package for the Social Sciences (SPSS), Version 24. Statistics included means and standard deviations for chronological age, frequencies and percentages of patients in CV stages, and comparisons of proportions through chi-square tests. Statistical significance was considered at Type I error alpha $\leq 0.5$.

\section{RESULTS:}

Skeletal maturity was categorized into six stages, depending on the morphological changes in the three vertebrae (C2, C3 and C4) and the differences in their shape. Patients' chronological age was not known during the process of identifying their skeletal maturity stage. The cervical maturation stages were as follows.

- CVMS 1 -Growth peak is expected to occur at least two years after this stage.

- CVMS 2 -Growth peak is predicted to occur one year after this stage.

- CVMS 3 - Growth peak occurs during this stage.

- CVMS 4 -Growth peak has occurred not later than one year before this stage.

- CVMS 5 - Growth peak has occurred at least one year after this stage.

- CVMS 6 - Growth peak was completed at least two years after this stage.

The distribution of patients among the six skeletal maturation stages for the whole sample and the two genders are given in Table 1 below. The proportions of male and female patients in each stage were not significantly different ( $p>0.05$ for all 6 comparisons). The most prevalent CVM stages among the female patients were $6(31.4 \%), 5(23.5 \%)$ and $4(19.6 \%)$. The majority of the male patients were in CMV stages 5 (26.1\%), 6(21.7\%), and 2 (17.4). Overall, the most frequent CMV stages among the girls were of higher skeletal maturity compared with the most frequent CVM stages among the boys.

Table 1. Number and \% of patients in each CVM stage.

\begin{tabular}{|c|c|c|c|c|}
\hline CVS & Whole sample & Female & Male & Sig \\
\hline 1 & $\begin{array}{c}5 \\
(6.8 \%)\end{array}$ & $\begin{array}{c}3 \\
(5.9 \%)\end{array}$ & $\begin{array}{c}2 \\
(8.7 \%)\end{array}$ & .64 \\
\hline 2 & $\begin{array}{c}7 \\
(9.5 \%)\end{array}$ & $\begin{array}{c}3 \\
(5.9 \%)\end{array}$ & $\begin{array}{c}4 \\
(17.4)\end{array}$ & .13 \\
\hline 3 & $\begin{array}{c}10 \\
(13.5)\end{array}$ & $\begin{array}{c}7 \\
(13.7 \%)\end{array}$ & $\begin{array}{c}3 \\
(13 \%)\end{array}$ & .908 \\
\hline 4 & $\begin{array}{c}13 \\
(17.6 \%)\end{array}$ & $\begin{array}{c}10 \\
(19.6 \%)\end{array}$ & $\begin{array}{c}3 \\
(13 \%)\end{array}$ & .52 \\
\hline 5 & $\begin{array}{c}18 \\
(24.3 \%)\end{array}$ & $\begin{array}{c}12 \\
(23.5 \%)\end{array}$ & $\begin{array}{c}6 \\
(26.1 \%)\end{array}$ & .78 \\
\hline 6 & $\begin{array}{c}21 \\
(28.4 \%)\end{array}$ & $\begin{array}{c}16 \\
(31.4 \%)\end{array}$ & $\begin{array}{c}5 \\
(21.7 \%)\end{array}$ & .37 \\
\hline
\end{tabular}


The results for the female patients (Table 2) reveal that consistencies were prevalent in the female subjects after growth spurt $(79 \%)$, whereas in the group before growth spurt they amounted to $33 \%$. The difference between the two age groups was statistically significant, $\chi 2$ (1) = $10.635, p=0.001$. The opposite tendency was observed re- garding the discrepancies between chronological age and skeletal maturity, which constituted a statistically higher proportion $(67 \%)$ in the group before age spurt as compared to $21 \%$ in the group after the growth spurt, $\chi^{2}(1)=$ $10.635, p=0.001$.

Table 2. Consistencies and discrepancies between female patients' chronological age and skeletal maturity before and after the growth spurt.

\begin{tabular}{cccccccc}
\hline Age Group & $\mathrm{N}$ & Consistencies & $\begin{array}{c}\chi^{2} \\
(\mathrm{df} 1)\end{array}$ & Sig & Discrepancies & $\begin{array}{c}\chi^{2} \\
(\mathrm{df} 1)\end{array}$ & Sig \\
\hline $9.0-13.50$ & 27 & $33 \%$ & & & & & \\
& & & 10.635 & $.001^{* *}$ & & 10.635 & $.001^{* *}$ \\
$13.75-17$ & 24 & $79 \%$ & & & $21 \%$ & & \\
\hline
\end{tabular}

** Statistical significance at alpha $=.01 ; *$ Statistical significance at alpha $=.05$

Among the male patients, the observed trend was similar to their female counterparts (Table 3). The patients after growth spurt showed a significantly higher percentage $(87.5 \%)$ of consistency between chronological age and skeletal maturity than those before the growth spurt, $\chi^{2}$ (1)
$=7.418, p=0.006$. Contrariwise, the rate of discrepancies was significantly higher $(73.4 \%)$ among male patients before growth spurt as compared to the ones after growth spurt $(12.5 \%), \chi^{2}(1)=7.418, p=0.006$.

Table 3. Consistencies and discrepancies between male patients' chronological age and skeletal maturity before and after the growth spurt

\begin{tabular}{cccccccc}
\hline Age Group & $\mathrm{N}$ & Consistencies & $\begin{array}{c}\chi^{2} \\
(\mathrm{df} 1)\end{array}$ & Sig & Discrepancies & $\begin{array}{c}\chi^{2} \\
(\mathrm{df} 1)\end{array}$ & Sig \\
\hline $9.0-13.50$ & 15 & $26.6 \%$ & & & $73.4 \%$ & & \\
$13.75-17$ & 8 & $87.5 \%$ & 7.418 & $.006 * *$ & $12.5 \%$ & 7.418 & $.006^{* *}$ \\
\hline
\end{tabular}

$* *$ Statistical significance at alpha $=.01 ; *$ Statistical significance at alpha $=.05$

The percentages of consistency and discrepancy between the two sexes were compared within the groups before and after growth spurt through the chi-square test. In the group before the growth spurt, the female patients showed $33 \%$ consistency and $67 \%$ discrepancy, whereas the male patients had $26.6 \%$ consistency and $73.4 \%$ discrepancy, with no significant difference between the two sexes, $p=0.64$. In the group after the growth spurt, the female patients showed the consistency of $79 \%$ and discrepancy of $21 \%$ vs $87.5 \%$ consistency and $12.5 \%$ discrepancy among the male patients. The proportional distribution be- tween the two sexes was not statistically significant, $p=$ 0.60 .

The overall percentages of consistency and discrepancy in the whole sample were examined for statistically significant sex differences through the chi-square test. The discrepancies were coded into two categories:1) towards a lower CVM stage than expected; and 2) towards a higher CVM stage than expected (Table 4). The female patients showed 54\% consistency and 46\% discrepancy vs $48 \%$ consistency and $52 \%$ discrepancy among the male patients. The difference was not statistically significant, $p=0.73$. 
Table 4. Summary of the consistency and discrepancy between chronological age and skeletal maturity among the female and male patients.

\begin{tabular}{|c|c|c|c|c|c|c|c|c|c|}
\hline \multirow[t]{2}{*}{ Sex } & & \multicolumn{3}{|c|}{ Consistency } & \multicolumn{3}{|c|}{ Discrepancy } & \multirow[b]{2}{*}{$\begin{array}{c}\text { Higher } \\
\text { CVS }\end{array}$} & \multirow[b]{2}{*}{ Sig. } \\
\hline & & $\begin{array}{c}\text { Both age } \\
\text { Groups }\end{array}$ & Sig. & $\begin{array}{c}\text { Both age } \\
\text { groups }\end{array}$ & Sig. & $\begin{array}{l}\text { Lower } \\
\text { CVS }\end{array}$ & Sig. & & \\
\hline \multirow[t]{3}{*}{ Female } & $\mathrm{N}$ & 28 & & 23 & & 4 & & 19 & \\
\hline & $\%$ & $54 \%$ & & $46 \%$ & & $17 \%$ & & $83 \%$ & \\
\hline & & & .73 & & .73 & & .56 & & .56 \\
\hline \multirow[t]{2}{*}{ Male } & $\mathrm{N}$ & 11 & & 12 & & 3 & & 9 & \\
\hline & $\%$ & $48 \%$ & & $52 \%$ & & $25 \%$ & & $75 \%$ & \\
\hline
\end{tabular}

Although the female patients had a smaller percentage of discrepancies towards a lower CVMS (17\%) and a higher percentage towards a higher CVMS $(83 \%)$ than the male patients (25\% towards lower and $75 \%$ towards higher CVMS), the difference was not statistically significant, $p$ $=0.56$.

\section{DISCUSSION:}

In this study, we investigated the relationship between chronological age and skeletal maturity in female and male patients before and after the growth spurt. We found a significant discrepancy between chronological and skeletal age in the patients before growth spurt regardless of their sex. The percentage of consistency was significantly higher for both female and male patients after the growth spurt. This finding collaborates with previous claims about the low reliability of chronological age as a predictor of biological maturity and affirms skeletal maturity as a stronger and more reliable method [8, $13]$.

Another variable of interest to our investigation was the patients' sex which is considered an important factor in orthodontic treatment, based on findings which show that females and males differ in their biological development. It has been reported that females are more advanced than males in skeletal maturation in the pre-adolescent years [14] and that females are on average 1 to 6 months ahead of males [5] in their development. In a more recent study, Baidas [8] examined sexual dimorphism in relation to chronological age and skeletal maturity and found that Saudi female patients were more advanced than male patients at each one of the six CVM stages of skeletal maturity. According to Ozer et al. girls have a shorter puberty peak period than boys and complete their maturation earlier [2]. Demirjian and Levesque report that girls transition through maturation stages is faster than boys [5].
On the other hand, there are also studies with mixed results, some of which report accelerated maturation in males. For instance, Finnish authors' observed a greater dental acceleration in girls compared to boys [7], whereas Thai researchers [15] found a greater dental acceleration in boys. Rozylo-Kalinowska et al. [16] did not detect statistically significant differences between boys and girls of ages $6,13,14$ and 15; however, in the age range $7-12$ years, a more pronounced accelerated development was observed in girls. Holtgrave et al. [6] found a developmental advancement in girls but not throughout the entire maturation process. In the age range of 5 - 9 years, boys showed an acceleration in the dental development of 6-9 months.

In our comparison of female and male patients' consistencies and discrepancies between chronological age and skeletal maturity, we did not find significant evidence in support of sexual dimorphism. Our results support the findings of Calfee et al. [17] which showed a higher percentage of discrepancies between chronological age and skeletal maturation among boys, however, in the present study, the difference was much smaller. The discrepancy rate was $52 \%$ among boys and $48 \%$ among girls, with no significant difference between the sexes.

In our study, the female patients showed a higher percentage of discrepancy towards a higher CVS (83\%) than the male patients who had $75 \%$ discrepancy towards a higher CVM stage, but the difference was not significant. In Calfee et al. [17], the discrepancy towards a higher maturity stage was $77 \%$ among boys and $54 \%$ among girls.

Contrary to Baidas's (2012) [8] study our female and male patients showed great similarity in average mean age at each CVM stage. The similarity is illustrated in Figure 1 , where the line plots of the female and male mean age overlap or are very close to each other. 
Fig. 1. Mean age of female and male patients at each of the six CVM stages.

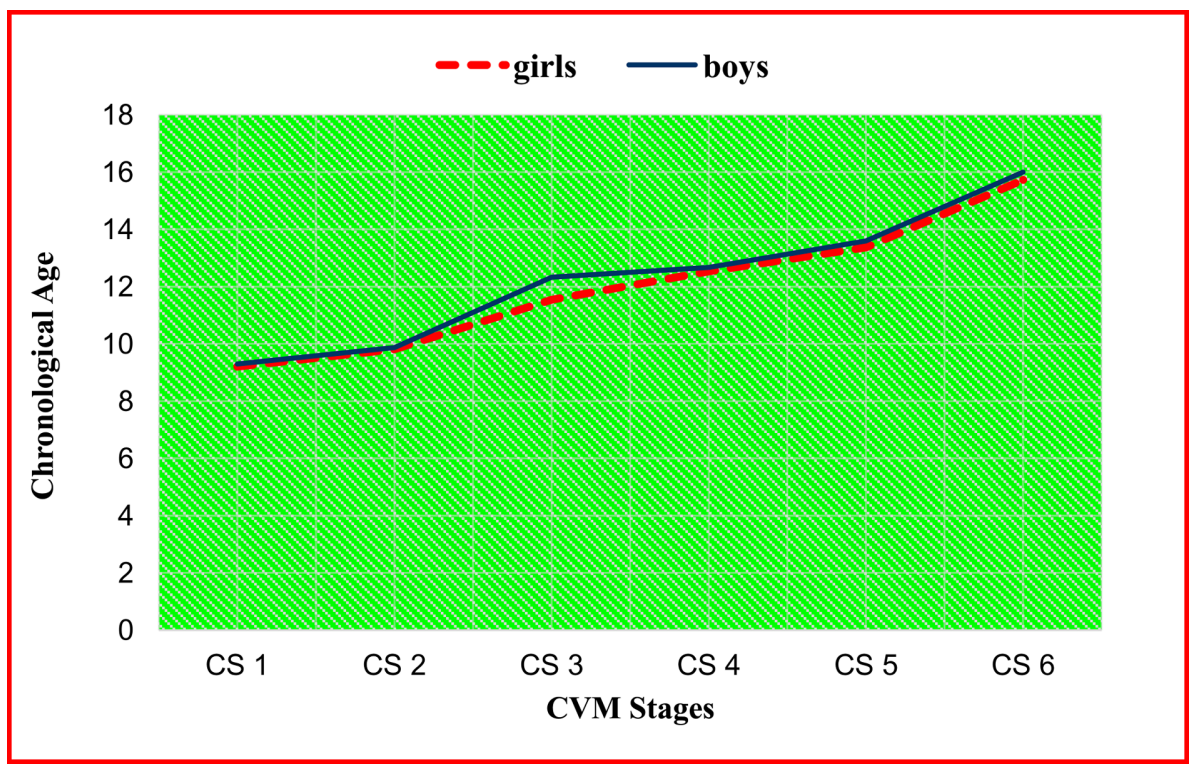

However, we found one similarity with Baidas's [8] study in that the majority of the female patients were in more advanced CVM stages than the majority of the male patients. Specifically, the most frequent CVM stages among the girls were 6, 5 and 4, whereas, among the boys, the most frequent CVM stages included 5, 6 and 2.

The studies of Mack et al., Hedayati et al. and Costacurta et al. revealed accelerated dental development in overweight and obese children, but the examined sample did not demonstrate significant accelerated skeletal maturation [18, 19, 20]. These results motivate us to prefer the assessment of skeletal age through cervical vertebral maturation development.

The lack of clearly expressed sexual dimorphism in our study can have more than one explanation. The skeletal maturation of adolescents is influenced by many factors. Both sexes are subjected to varying degrees of environmental influences that can accelerate or slow down growth maturation processes. Such factors can be environmental, socioeconomic, dietary and lifestyle habits. Race and ethnicity may also influence the maturation process. For instance, our patients were approximately in the same age range as the ones in Baidas's study [8]; however in our sample the majority of the patients were at higher CV maturation stages (6, 5 and 4 among the females; 5, 6 and 2 among the males) as compared to the CVM stages reported by Baidas (3 and 5 among females; 1, 2 and 3 among males). The difference in skeletal maturity level may be linked to the different ethnic, geographic, and societal background of our patients and those in Baidas's study [8].
Also, in more recent years an accelerated rate of maturation among adolescents is observed which may explain the difference between earlier studies, where females were more advanced than males in skeletal maturation [14]. Our patients were born between 1999 and 2008 in a different time period than the one in the abovementioned studies.

\section{CONCLUSION:}

Based on the results of our study, we have extrapolated the following main conclusions:

1) Chronological age is a feeble indicator of skeletal maturity in both female and male Bulgarian adolescents. The discrepancy rate is particularly high in patients before growth spurt in both sexes.

2) Bulgarian adolescents' skeletal maturation stage has a weak connection with their sex. Sexual dimorphism is vaguely expressed in the consistencies and discrepancies between chronological age and skeletal maturity. However, the most frequent CVÌ stages differ among females and males. Higher skeletal maturity stages $(6,5$ and 4) are prevalent among female adolescent's vs lower CVÌ stages $(5,6$ and 2$)$ among male adolescents.

3) The above conclusions are of practical importance for the clinical practice. They should be considered in the planning and scheduling of individual patients' orthodontic treatment. Generalizations based on a patient's chronological age and sex should be avoided since they are not reliable indicators of a patient's maturity stage and growth potential. Different factors should be considered in determining the best treatment plan for each individual patient. 


\section{REFERENCES:}

1. Björk A, Helm S. Prediction of the age of maximum puberal growth in body height. Angle Orthod. 1967 Apr; 37(2):134-43. [PubMed]

2. Ozer T, Kama JD, Ozer SY. A practical method for determining pubertal growth spurt. Am J Orthod Dentofacial Orthop. 2006 Aug;130(2):131.e1-6. [PubMed] [CrossRef]

3. Baccetti T, Franchi L, McNamara JA Jr. An improved version of the cervical vertebral maturation (CVM) method for the assessment of mandibular growth. Angle Orthod. 2002 Aug; 72(4):316-23. [PubMed]

4. Wei C, Gregory JW. Physiology of normal growth. Paediatr Child Health. 2009 May;19(5):236-40. [CrossRef]

5. Demirjian A, Levesque GY. Sexual differences in dental development and prediction of emergence. $J$ Dent Res. 1980 Jul;59(7):1110-22. [PubMed] [CrossRef]

6. Holtgrave EA, Kretschmer $\mathrm{R}$, Müller R. Acceleration in dental development: fact or fiction. Eur $J$ Orthod. 1997 Dec;19(6):703-10. [PubMed]

7. Nyström M, Aine L, Peck L, Haavikko K, Kataja M. Dental maturity in Finns and the problem of missing teeth. Acta Odontol Scand. 2000 Apr;58(2):49-56. [PubMed]

8. Baidas L. Correlation between cervical vertebrae morphology and chronological age in Saudi adoles- cents. King Saud Univ J Dent Sci. 2012 Jan;3(1):21-26. [CrossRef]

9. Lund E, Tommervold T. Relationship between dental age, skeletal maturity and chronological age in young orthodontic patients [dissertation]. The Arctic University of Norway. 2014. 14p.

10. Hilgers KK, Akridge M, Scheetz JP, Kinane DE. Childhood obesity and dental development. Pediatr Dent. 2006 Jan-Feb;28(1):1822. [PubMed]

11. Baccetti T, Franchi L, McNamara JA Jr. The Cervical Vertebral Maturation (CVM) Method for the Assessment of Optimal Treatment Timing in Dentofacial Orthopedics. Semin Orthod. 2005 Sep;11(3):119-129. [CrossRef]

12. Lamparski DG. Skeletal age assessment utilizing cervical vertebrae [dissertation]. [Pittsburgh (PA)]: University of Pittsburgh; 1972.

13. Safavi SM, Beikaii $H$, Hassanizadeh R, Younessian F, Baghban AA. Correlation between cervical vertebral maturation and chronological age in a group of Iranian females. Dent Res J (Isfahan). 2015 SepOct;12(5):443-8. [PubMed]

14. Hunter CJ. The correlation of facial growth with body height and skeletal maturation at adolescence. Angle Orthod. 1966 Jan;36(1):44-54. [PubMed]

15. Krailassiri S, Anuwongnukroh
N, Dechkunakorn S. Relationships between dental calcification stages and skeletal maturity indicators in Thai individuals. Angle Orthod. 2002 Apr; 72(2):155-66. [PubMed]

16. Rozylo-Kalinowska I, Kiworkowa-Raczkowska E, Kalinowski P. Dental age in central Poland. Forensic Sci Int. 2008 Jan; 174(2-3):20716. [PubMed] [CrossRef]

17. Calfee RP, Sutter M, Steffen JA, Goldfarb CA. Skeletal and chronological ages in American adolescents: current findings in skeletal maturation. J Child Orthop. 2010 Oct;4(5): 467-70. [PubMed] [CrossRef]

18. Costacurta M, Sicuro L, Di Renzo L, Condò R, De Lorenzo A, Docimo R. Childhood obesity and skeletal-dental maturity. Eur $J$ Paediatr Dent. 2012 Jun;13(2):12832. [PubMed]

19. Mack KB, Phillips C, Jain N, Koroluk LD. Relationship between body mass index percentile and skeletal maturation and dental development in orthodontic patients. Am $J$ Orthod Dentofacial Orthop. 2013 Feb; 143(2):228-34. [PubMed] [CrossRef]

20. Hedayati Z, Khalafinejad F. Relationship between Body Mass Index, Skeletal Maturation and Dental Development in 6- to 15- Year Old Orthodontic Patients in a Sample of Iranian Population. J Dent (Shiraz). 2014 Dec;15(4):180-6. [PubMed]

Please cite this article as: Stoilova-Todorova M, Krasteva S, Stoilov G, Todorova-Plachiyska K. Comparison of Skeletal Maturity and Chronological Age in Bulgarian Female and Male Patients with Transverse Maxillary Deficit. $J$ of IMAB. 2018 Jul-Sep;24(3):2119-2124. DOI: https://doi.org/10.5272/jimab.2018243.2119

Received: 03/05/2018; Published online: 21/08/2018

\author{
Address for correspondence: \\ Mariya Georgieva Stoilova-Todorova \\ Department of Orthodontics, Faculty of Dental Medicine, Medical University of \\ Plovdiv. \\ 3, Hristo Botev Blvd., 4000 Plovdiv, Bulgaria \\ E-mail: marchela_stoilova@abv.bg
}

